\title{
Fibroblast Growth Factor 2 in the Dorsomedial Striatum Is a Novel Positive Regulator of Alcohol Consumption
}

\author{
Oren Even-Chen, ${ }^{1}$ ㅇossi Sadot-Sogrin, ${ }^{2}$ Ohad Shaham, ${ }^{1}$ and ${ }^{\circledR} S e g e v$ Barak ${ }^{1,2}$ \\ ${ }^{1}$ School of Psychological Sciences and ${ }^{2}$ Sagol School of Neuroscience, Tel Aviv University, 69978 Tel Aviv, Israel
}

\begin{abstract}
Repeated alcohol intake leads to mesostriatal neuroadaptations, resulting in drinking escalation and addiction phenotypes. Fibroblast growth factor 2 (FGF2) has been shown to interact with the mesostriatal dopaminergic system, and has been implicated in the actions of psychostimulants in the brain, and in several psychiatric disorders. Here, we report on a positive regulatory feedback loop of alcohol and FGF2 in rodent models. Specifically, we found that acute alcohol exposure $(2.5 \mathrm{~g} / \mathrm{kg}$, i.p.) increased the mRNA expression of $F g f 2$ in the dorsal hippocampus, nucleus accumbens, and dorsal striatum. Longer alcohol exposure $(7 \mathrm{~d} \times 2.5 \mathrm{~g} / \mathrm{kg}$, i.p.) restricted these increases to the dorsal striatum, and the latter effect was blocked by the dopamine D2-like receptor antagonist haloperidol. Voluntary prolonged and excessive alcohol consumption in a 2-bottle choice procedure increased Fgf2 expression selectively in dorsomedial striatum (DMS) of both mice and rats. Importantly, we found that systemic administration of recombinant FGF2 (rFGF2) in mice, or rFGF2 infusion into the dorsal striatum or DMS of rats, increased alcohol consumption and preference, with no similar effects on saccharin or sucrose consumption. Finally, we found that inhibition of the endogenous FGF2 function in the DMS, by an anti-FGF2 neutralizing antibody, suppressed alcohol consumption and preference. Together, our results suggest that alcohol consumption increases the expression of Fgf 2 in the DMS, and that striatal FGF2 promotes alcohol consumption, suggesting that FGF2 in the DMS is a positive regulator of alcohol drinking.
\end{abstract}

Key words: addiction; alcohol; dopamine; dorsomedial striatum; fibroblast growth factor 2

Significance Statement

Long-term alcohol intake may lead to neuroadaptations in the mesostriatal reward system, resulting in addiction phenotypes. Fibroblast growth factor 2 (FGF2) is crucial for the development and maintenance of the mesostriatal dopaminergic system. Here, we provide evidence for the involvement of FGF2 in alcohol-drinking behaviors. We show that alcohol increases Fgf2 expression in the dorsal striatum, an effect mediated via dopamine D2-like receptors. Importantly, we show that infusion of recombinant FGF2 into the dorsomedial striatum increases alcohol consumption, whereas inhibiting the endogenous FGF2 function suppresses consumption. Thus, FGF2 is an alcohol-responsive gene constituting a positive regulatory feedback loop with alcohol. This loop leads to facilitation of alcohol consumption, marking FGF2 as a potential new therapeutic target for alcohol addiction.

\section{Introduction}

Alcohol use disorder (AUD) is a chronic and relapsing psychiatric disorder affecting $\sim 6 \%-10 \%$ of the population (American Psychiatric Association, 2013; World Health Organization, 2014), characterized by excessive, out of control alcohol consumption and emergence of withdrawal syndrome during alcohol abstinence

\footnotetext{
Received March 31, 2017; revised July 16, 2017; accepted July 31, 2017.

Author contributions: 0.E.-C. and S.B. designed research; 0.E.-C., Y.S.-S., O.S., and S.B. performed research; O.E.-C. and S.B. analyzed data; $0 . E$.-C. and S.B. wrote the paper.

This work was supported by Israel Science Foundation Grants $968-13$ and 1916-13 to S.B., German Israeli Foundation Grant I-2348-105.4/2014 to S.B., and National Institute of Psychobiology in Israel 110-14-15 to S.B.

The authors declare no competing financial interests.

Correspondence should be addressed to Dr. Segev Barak, School of Psychological Sciences, Sagol School of Neuroscience, Tel Aviv University, Tel Aviv 69978, Israel. E-mail: barakseg@post.tau.ac.il.

DOI:10.1523/JNEUROSCI.0890-17.2017

Copyright $\odot 2017$ the authors $\quad 0270-6474 / 17 / 378742-13 \$ 15.00 / 0$
}

(American Psychiatric Association, 2013). Alcohol consumption induces neuroadaptations in the brain reward system (i.e., the mesocorticolimbic dopaminergic system), which projects from the ventral tegmental area (VTA) to the nucleus accumbens (NAc), hippocampus, amygdala, and prefrontal cortex (PFC) (Koob and Volkow, 2009; Spanagel, 2009). These neuroadaptations are thought to account for the altered reward function in AUD (Berridge and Robinson, 1998; Nestler, 2001; Russo et al., 2010; Koob, 2013).

It is increasingly accepted that the nigrostriatal system, which projects from the substantia nigra to the dorsal striatum, plays a pivotal role in goal-directed behaviors, as well as in the habitual and compulsive nature of alcohol addiction (Wise, 2009; Everitt and Robbins, 2013). Thus, research using rodent models has shown that excessive alcohol intake leads to alterations in gene expression and signaling pathways in the dorsal striatum (e.g., 
McGough et al., 2004; Jeanblanc et al., 2006; Wang et al., 2007), and these alterations play a crucial role in subsequent alcoholdrinking behaviors (Wang et al., 2007, 2011; Jeanblanc et al., 2009; Logrip et al., 2014; Ron and Barak, 2016).

Fibroblast growth factor 2 (FGF2), a member of the FGF family consisting of 22 members, is implicated in brain development (Walicke et al., 1986; Ford-Perriss et al., 2001; Reuss and von Bohlen und Halbach, 2003), adult neurogenesis (Wagner et al., 1999), and regenerative plasticity (Gómez-Pinilla et al., 1995). In particular, FGF2 is involved in the development and maintenance of midbrain dopaminergic neurons (Reuss and Unsicker, 2000; Reuss and von Bohlen und Halbach, 2003; Grothe and Timmer, 2007).

The psychostimulants cocaine and amphetamine have been shown to increase FGF2 levels in several brain regions. Specifically, cocaine treatment upregulates Fgf2 mRNA levels in the striatum, PFC, and hippocampus (Fumagalli et al., 2006), and repeated administration of amphetamine leads to long-lasting increases in FGF2 immunoreactivity in the VTA and substantia nigra (Flores and Stewart, 2000a). FGF2 expression positively correlates with the magnitude of psychostimulants-induced locomotor sensitization (Flores and Stewart, 2000a), considered to model addiction-related neuroadaptations (Robinson and Berridge, 2001). Furthermore, repeated administration of amphetamine results in an FGF2-mediated increase in dendritic growth of VTA dopaminergic neurons (Mueller et al., 2006). Together, these findings indicate that FGF2 is involved in the development of psychostimulant sensitization and may be involved in molecular mechanisms relevant to addiction.

Here, we tested whether alcohol exposure alters the expression of Fgf 2 in mesolimbic and nigrostriatal brain regions, and if so, whether FGF2 regulates alcohol intake.

\section{Materials and Methods}

Animals

Male and female C57BL/6J mice and Wistar rats (20-25 g and 175-200 g at the beginning of experiments, respectively) were bred in Tel Aviv University animal facility and housed under a $12 \mathrm{~h} \mathrm{light/dark} \mathrm{cycle} \mathrm{(mice}$ lights on at 4:00 A.M., rats lights on at 7:00 A.M.) with food and water available ad libitum. Animals were individually housed, except for alcohol-injection experiments, in which mice were housed 4 per cage. All experimental protocols conformed to the guidelines of the Institutional Animal Care and Use Committee of Tel Aviv University and of the National Institutes of Health. All efforts were made to minimize the number of animals and their suffering.

\section{Reagents and drug preparation}

Fast SYBR Green Master Mix (\#4385617), TRIzol reagent (\#13150101), and RevertAid kit (\#0442) were supplied by Thermo-Fisher Scientific. DNA oligonucleotides (qRT-PCR primers), haloperidol (\#H1512), and isopropanol (\#563935) were obtained from Sigma-Aldrich. Isoflurane was obtained from Piramal Critical Care. Neutralizing antibody against FGF2 (05-117) and control IgG (12-371) were purchased from Millipore. Ethyl alcohol (absolute), purchased from Gadot, was diluted to $20 \%$ alcohol (vol/vol) in saline (for alcohol injection) or in tap water (for voluntary consumption). Haloperidol was dissolved in saline containing $0.1 \%$ acetic acid; $\mathrm{pH}$ was corrected to 6.0 with $\mathrm{NaOH}$. Recombinant FGF2 (rFGF2) was purchased from Prospec (\#CYT-386) and dissolved in PBS containing $0.1 \%$ BSA.

\section{Quantitative reverse transcriptase polymerase chain} reaction ( $q R T-P C R)$

Following brain dissection, tissue samples were immediately snap-frozen in liquid nitrogen and stored at $-80^{\circ} \mathrm{C}$ until use. Frozen tissues were mechanically homogenized in TRIzol reagent and total RNA was isolated from each sample according to the manufacturer's recommended pro- tocol. mRNA was reverse transcribed to cDNA using the Reverse Transcription System and RevertAid kit. Plates of 96 wells were prepared for the SYBR Green cDNA analysis using Fast SYBR Master Mix. Samples were analyzed in triplicate with a Real-Time PCR System (StepOnePlus; Applied Biosystems), and quantified against an internal control gene, Gapdh. We used the following reaction primers sequences: mice; Fgf2 forward, 5' -CGT CAA ACT ACA ACT CCA AGCAG-3'; reverse, 5' -TCC AGT CGT TCA AAG AAG AAA CAC-3'; Gapdh forward, 5' -CCA GAA CAT CAT CCC TGC-3'; reverse, $5^{\prime}$-GGA AGG CCA TGC CAG TGAGC-3'; rats; Fgf2 forward, 5'-AGT TGT GTC CAT CAA GGG ATGT-3'; reverse, 5' -AGC CAG CAG CCG TCCAT-3'; Gapdh forward, 5'-GCA AGA GAG AGG CCC TCAG-3'; reverse, 5'-TGT GAG GGA GAT GCT CAGTG-3'. Thermal cycling was initiated with incubation at $95^{\circ} \mathrm{C}$ for $20 \mathrm{~s}$ (for SYBR Green activation), followed by 40 cycles of PCR with the following conditions: heating at $95^{\circ} \mathrm{C}$ for $3 \mathrm{~s}$ and then $30 \mathrm{~s}$ at $60^{\circ} \mathrm{C}$. Relative quantification was calculated using the $\Delta \Delta \mathrm{C}_{\mathrm{t}}$ method.

Intermittent access to $20 \%$ alcohol in 2-bottle choice (IA2BC)

After 1 week of habituation for individual housing, mice or rats were trained to consume alcohol in the IA2BC procedure as previously described (Neasta et al., 2010; Hwa et al., 2013; Warnault et al., 2013; Carnicella et al., 2014). Briefly, animals received three 24-h sessions of free access to 2-bottle choice per week (tap water and 20\% alcohol v/v) on Sundays, Tuesdays, and Thursdays, with 24 or 48 h of alcohol-deprivation periods between the alcohol-drinking sessions. During the withdrawal periods, animals received only water. The position (left or right) of each solution was alternated between each session to control for side preference. Water and alcohol bottles were weighed before and after each alcohol-drinking session, and consumption levels were normalized to body weight. Training lasted 5 weeks for mice, and 7 weeks for rats, before the brain tissue collection, surgical or pharmacological manipulations.

\section{Intermittent access to saccharin or sucrose in 2-bottle choice}

This procedure was conducted as previously described (Warnault et al., 2013). Training was similar to the IA2BC procedure described above, except that mice had access to saccharin $(0.005 \%$ and $0.03 \% \mathrm{w} / \mathrm{v})$ or sucrose $(0.2 \%$ and $1 \% \mathrm{w} / \mathrm{v})$ solutions instead of alcohol, and training lasted 3 weeks before rFGF2 treatment. Solutions intake was normalized to body weight.

\section{Surgery and intracerebral microinfusion}

Surgery and microinfusion were conducted as previously described (Barak et al., 2011a, b, 2013; Ahmadiantehrani et al., 2014). Rats were anesthetized continuously with isoflurane and mounted on a stereotaxic apparatus (Kopf Instruments). Guide cannulae (26 gauge; Plastics One) were aimed dorsal to the target areas: dorsal striatum (in millimeters relative to bregma: 1.2 anteroposterior, \pm 2.5 mediolateral, -3.9 dorsoventral) and dorsomedial striatum (DMS; 1.2 anteroposterior, \pm 1.5 mediolateral, -4.4 dorsoventral), according to the Rat Brain Atlas (Paxinos and Watson, 2007). The DMS coordinates were chosen based on Jeanblanc et al. (2009). After recovery, habituation to the microinfusion procedure, and reestablishment of baseline consumption levels (3 weeks), rFGF2 (200 ng/0.75 $\mu \mathrm{l} /$ hemisphere), or anti-FGF2 neutralizing antibody (750 ng/0.75 $\mu \mathrm{l} / \mathrm{hemisphere),} \mathrm{or} \mathrm{corresponding} \mathrm{vehicle,} \mathrm{was} \mathrm{infused} \mathrm{in}$ gently restrained rats over $1.5 \mathrm{~min}$ via injection cannula (33 gauge, Plastics One), extending $0.5 \mathrm{~mm}$ beyond the guide cannula tip into the target region. Injection cannulae were left in place for 2 additional minutes. rFGF2 concentration was based on previous studies (Turner et al., 2008; Graham and Richardson, 2011). The concentration of anti-FGF2 neutralizing antibody was chosen based on Hafenbreidel et al. (2015).

\section{Histology}

Locations of cannulae were verified in $30 \mu \mathrm{m}$ coronal sections of PFAfixed tissue stained with cresyl violet. Only data from subjects with cannulae located in the region of interest were included in the analysis.

\section{Experimental design and statistical analysis}

Sex approximately equally distributed across experiments and was initially analyzed as a factor; however, all analyses did not yield a main effect 


\section{A Acute treatment}

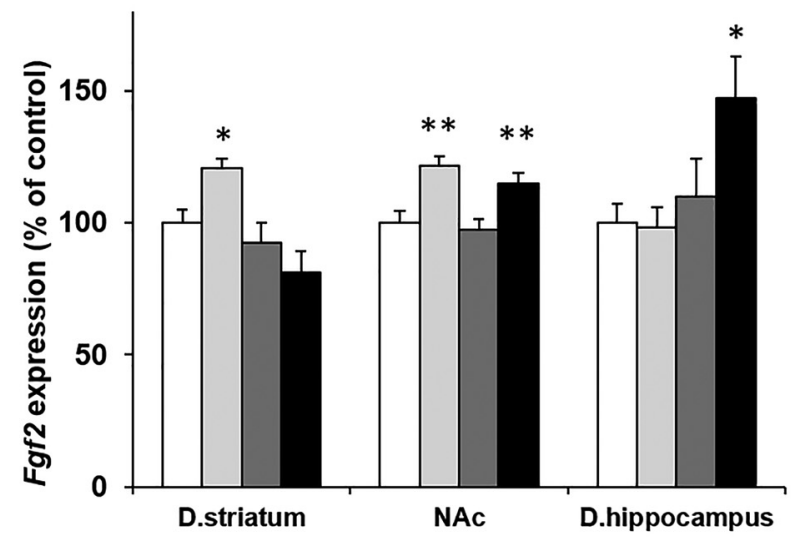

$\square$ Saline $\square$ Alcohol $2 \mathrm{~h} \quad \square$ Alcohol $6 \mathrm{~h} \quad \square$ Alcohol $24 \mathrm{~h}$

\section{B Sub-chronic treatment}

\section{Location of sampling regions}
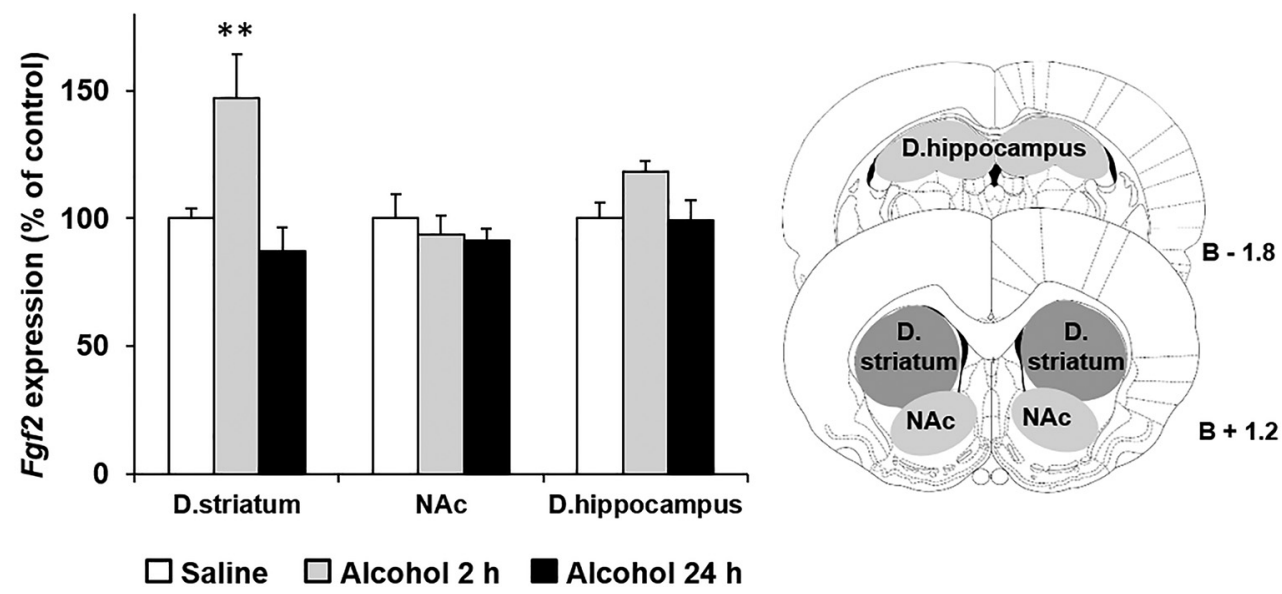

Figure 1. Alcohol exposure alters Fgf2 expression in the dorsal striatum (D.striatum), nucleus accumbens (NAc), and dorsal hippocampus (D.hippocampus). $A, A l c o h o l ~(2.5 \mathrm{~g} / \mathrm{kg}, 20 \%$, i.p.) or saline was administered once, $2 \mathrm{~h}$ (Alcohol $2 \mathrm{~h}$ ), $6 \mathrm{~h}$ (Alcohol $6 \mathrm{~h}$ ), or $24 \mathrm{~h}$ (Alcohol $24 \mathrm{~h}$ ) before brain tissue collection. $n=5-8$ per group. B, Alcohol (2.5 g/kg, 20\%, i.p.) or saline was administered once a day for $7 \mathrm{~d}$. Brain tissues were collected $2 \mathrm{~h}$ (Alcohol $2 \mathrm{~h}$ ) or $24 \mathrm{~h}$ (Alcohol $24 \mathrm{~h}$ ) after the last alcohol injection. $n=5-10$ per group. $A, B, F g f 2$ mRNA levels were determined by qRT-PCR and normalized to Gapdh, which was not affected by alcohol on its own (Fig. 1-1, available at https://doi.org/10.1523/JNEUROSCI.0890-17.2017.f1-1). Bar graphs indicate mean + SEM. Each brain region was normalized to its saline control. C, Schematic representation of the sampling regions. ${ }^{*} p<0.05$ compared with saline control. ${ }^{* *} p<0.01$ compared with saline control.

of sex or any interaction with other factors ( $p$ values $>0.05$ ). Therefore, the data were collapsed across this factor. The rationale for the experiments is described in Results.

Fgf2 expression experiments. In these experiments, we tested the effects of alcohol exposure on $F g f 2$ expression in several brain regions. The mRNA expression of $\mathrm{Fg} 22$ was normalized to Gapdh expression (Zipori et al., 2017), which we found to be unaffected by alcohol in the protocols we used (Fig. 1-1, available at https://doi.org/10.1523/JNEUROSCI. 0890-17.2017.f1-1). Expression in each brain region was further normalized to its own control group (saline- or water-treated group).

First, we tested the effects of acute or subchronic alcohol administration on Fgf2 expression. Data were analyzed by one-way ANOVA, with a between-subjects factor of Time after the last alcohol injection. ANOVA was followed by Student-Newman-Keuls post hoc analyses throughout the study.

Next, we tested whether the effect of subchronic alcohol treatment on Fgf2 expression in the dorsal striatum was mediated by dopamine D2-like receptors. In this experiment, expression data were analyzed by two-way ANOVA, with between-subjects factors of Pretreatment (haloperidol, vehicle) and Treatment (alcohol, saline).

In the next set of experiments, we tested the effects of voluntary alcohol consumption on Fgf 2 expression. Mice were trained to consume alcohol in the IA2BC drinking protocol, and Fgf2 levels were determined at the end of a 24-h alcohol drinking session or of a 24-h alcohol-withdrawal session. Data were analyzed by one-way ANOVA, with a betweensubjects factor of Time point. Finally, we tested the effects of voluntary alcohol intake (IA2BC drinking protocol, in mice and rats) on Fgf2 expression in the dorsal striatum subregions: DMS and dorsolateral striatum (DLS). mRNA expression levels were measured at the end of a $24 \mathrm{~h}$ alcohol-withdrawal period and compared with a water-drinking control group by independent $t$ tests with a between-subjects factor of Time point.

Alcohol, saccharin, or sucrose consumption experiments. In this set of experiments, we tested the effects of rFGF2, administered systemically in mice, or infused into the dorsal striatum in rats, on the consumption and preference of the reward, as well as on water and total fluid intake.

First, we tested the effects of systemic rFGF2 or vehicle administration on alcohol $(20 \%)$, saccharin $(0.005 \%, 0.03 \%)$, or sucrose $(0.2 \%, 1 \%)$ consumption. In the alcohol consumption experiment, data were analyzed by independent $t$ tests (a between-subjects factor of Treatment). In the saccharin and sucrose experiments, data were analyzed by a $2 \times 2$ mixed-model ANOVA, with a between-subjects factor of Treatment (rFGF2, vehicle) and a within-subjects factor of solution Concentration. 
The effects of intracerebral rFGF2 on alcohol intake and preference, as well as on water and total fluid intake, were tested in a counterbalanced within-subjects design. Data were analyzed by paired-sample $t$ tests, with a within-subjects factor of Treatment.

Finally, we tested the effect of FGF2 inhibition on alcohol consumption. Anti-FGF2 neutralizing antibody and control IgG were infused into the rat DMS in a counterbalanced within-subjects design, and data were analyzed by paired-sample $t$ tests (a within-subjects factor of Treatment).

\section{Results}

\section{Acute and subchronic alcohol treatments increase Fgf2} mRNA expression

First, we tested whether acute alcohol treatment changes the mRNA expression of Fgf2. We focused on mesolimbic/striatal brain regions that were previously implicated in alcohol-drinking behaviors (Ron and Barak, 2016), namely, the NAc, dorsal striatum, and dorsal hippocampus. Mice received a single injection of alcohol $(2.5 \mathrm{~g} / \mathrm{kg}$ in a $20 \% \mathrm{alcohol} \mathrm{v} / \mathrm{v}$ solution, i.p.) or saline, and we dissected these brain regions 2,6 , and $24 \mathrm{~h}$ later.

We found that alcohol increased Fgf2 mRNA levels in a timeand brain region-specific manner (Fig. 1A). Specifically, we observed an increase in Fgf2 expression in the dorsal striatum $2 \mathrm{~h}$ after alcohol injection, but the expression levels of the growth factor returned to baseline levels $6 \mathrm{~h}$ after alcohol injection (oneway ANOVA, $F_{(3,33)}=6.46, p=0.002$; post hoc, $2 \mathrm{~h}$ vs saline, $p=$ 0.027). In addition, alcohol increased $F g f 2$ expression in the NAc 2 and $24 \mathrm{~h}$ (but not $6 \mathrm{~h}$ ) after alcohol injection (one-way ANOVA, $F_{(3,34)}=7.15, p=0.001$; post hoc, $2 \mathrm{~h}$ vs saline, $p=0.003$, or $24 \mathrm{~h}$ vs saline, $p=0.021)$. Finally, alcohol increased $F g f 2$ expression in the dorsal hippocampus $24 \mathrm{~h}$ after alcohol injection (one-way ANOVA, $F_{(3,26)}=4.71, p=0.01$; post hoc, 24 h vs saline, $p=0.011$ ).

Next, we determined the effects of a longer alcohol treatment on the expression of $F g f 2$. Mice were injected with alcohol $(2.5 \mathrm{~g} / \mathrm{kg}$ in a $20 \%$ alcohol v/v solution, i.p.) or saline once a day for $7 \mathrm{~d}$. Mice were killed 2 or $24 \mathrm{~h}$ after the last alcohol injection, as we did not observe any changes in $F g f 2$ expression at the $6 \mathrm{~h}$ time point following the acute treatment. As shown in Figure $1 B$, we found that this subchronic alcohol treatment also increased Fgf 2 mRNA levels in the dorsal striatum $2 \mathrm{~h}$, but not $24 \mathrm{~h}$ after the last alcohol injection (one-way ANOVA, $F_{(2,14)}=9.66, p=0.002$; post hoc, $2 \mathrm{~h}$ vs saline, $p=0.003$ ). No significant changes in the growth factor's expression were detected in the NAc or dorsal hippocampus ( $p$ values $>0.15$ )

Together, these data indicate that short alcohol exposure increases Fgf2 expression in the NAc, dorsal striatum, and dorsal hippocampus, brain regions that were previously implicated in alcohol-drinking behaviors (Koob and Volkow, 2016; Ron and Barak, 2016). However, more extended alcohol exposure restricts the increases in Fgf2 expression to the dorsal striatum.

\section{Dopamine D2-like receptors mediate the alcohol-induced increase in striatal $\mathbf{F g} \mathbf{2}$}

Alcohol has been shown to increase mesolimbic and nigrostriatal dopamine levels (Di Chiara and Imperato, 1988; Gonzales et al., 2004), and we show here that striatal Fgf2 expression is increased by alcohol. Furthermore, treatment with a dopamine D2 receptor (D2R) agonist was shown to increase $F g f 2$ mRNA expression, whereas agonists of the D1 or D3 receptors had no such effect (Fumagalli et al., 2003). Thus, we next tested whether the effects of alcohol on Fgf2 expression in the dorsal striatum are mediated by dopamine D2-like activation.

To test this possibility, we used the repeated alcohol injection protocol as above, which yielded an $\sim 50 \%$ increase in Fgf 2 mRNA

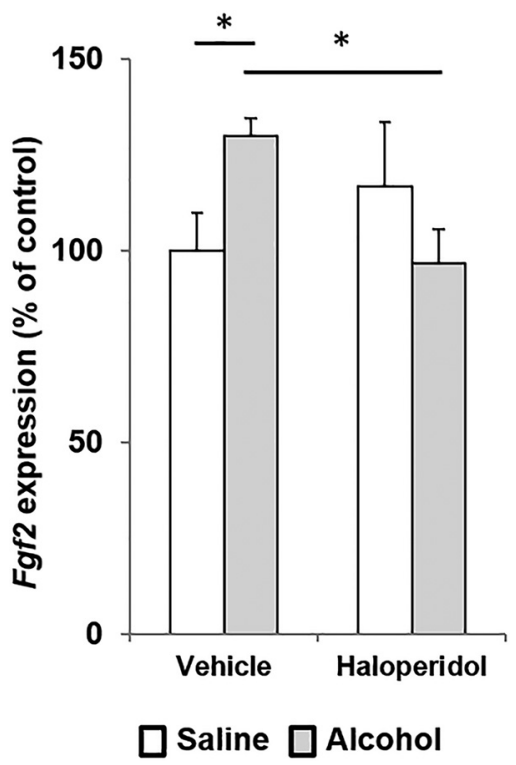

Figure 2. Alcohol-induced increase in Fgf2 expression in the dorsal striatum is mediated by dopamine D2-like receptors. Mice were pretreated with the dopamine D2-like receptor antagonist haloperidol ( $1 \mathrm{mg} / \mathrm{kg}$, i.p.) or vehicle, and $1 \mathrm{~h}$ later were treated with alcohol $(2.5 \mathrm{~g} / \mathrm{kg}$, $20 \%$, i.p.) or saline, once a day for $7 \mathrm{~d}$. The dorsal striatum was collected $2 \mathrm{~h}$ after the last alcohol injection. Fgf2 mRNA levels were determined by qRT-PCR and normalized to Gapdh, which was not affected by alcohol on its own (Fig. 1-1, available at https://doi.org/10.1523/JNEUROSCl. 0890-17.2017.f1-1). Bar graphs indicate mean + SEM, normalized to the saline + vehicle control group. $n=5-7$ per group. ${ }^{*} p<0.05$.

expression in the dorsal striatum $2 \mathrm{~h}$ after treatment (Fig. 1B). Therefore, we pretreated mice once a day for $7 \mathrm{~d}$ with the dopamine D2-like receptor antagonist haloperidol (1 mg/kg, i.p.) (Roceri et al., 2001) or vehicle. Each day, $1 \mathrm{~h}$ after haloperidol injection, mice received an alcohol $(2.5 \mathrm{~g} / \mathrm{kg}$ in a $20 \%$ alcohol v/v solution, i.p.) or saline injection. We then tested Fgf2 mRNA levels, $2 \mathrm{~h}$ after the last alcohol injection.

As shown in Figure 2, we found that alcohol treatment increased the expression of $F g f 2$ in the dorsal striatum, replicating our results above. However, haloperidol blocked the effect of alcohol and normalized Fgf2 expression. These results indicate that dopamine D2-like receptors mediate the alcohol-induced increases in Fgf2 expression in the dorsal striatum (two-way ANOVA; haloperidol Pretreatment $\times$ alcohol Treatment interaction, $\left.F_{(1,20)}=4.87, p=0.039\right)$ but no significant main effects of Pretreatment or Treatment ( $p$ values $>0.47$ ): post hoc, vehiclesaline vs vehicle-alcohol, $p=0.027$, and vehicle-alcohol vs haloperidol-alcohol, $p=0.015$ ).

\section{Voluntary alcohol consumption increases the expression of} Fgf 2 in the dorsal striatum

Next, we determined the effects of voluntary alcohol drinking on the expression of Fgf2. Mice were trained to consume alcohol in the IA2BC drinking procedure (Neasta et al., 2010; Warnault et al., 2013) for 5 weeks. In this drinking protocol, mice consume high quantities of alcohol, typically yielding an average alcohol consumption of $10-15 \mathrm{~g} / \mathrm{kg} / 24 \mathrm{~h}$, which generates blood alcohol concentration of $>100 \mathrm{mg} / \mathrm{dl}$ after binge-like drinking at the first hours of drinking (Hwa et al., 2011; Griffin, 2014; Ron and Barak, 2016). The NAc, dorsal striatum, and dorsal hippocampus of mice were collected at the end of a 24 -h alcohol drinking session (mean alcohol consumption: $\sim 10 \pm 0.75 \mathrm{~g} / \mathrm{kg} / 24 \mathrm{~h}$, alcohol pref- 

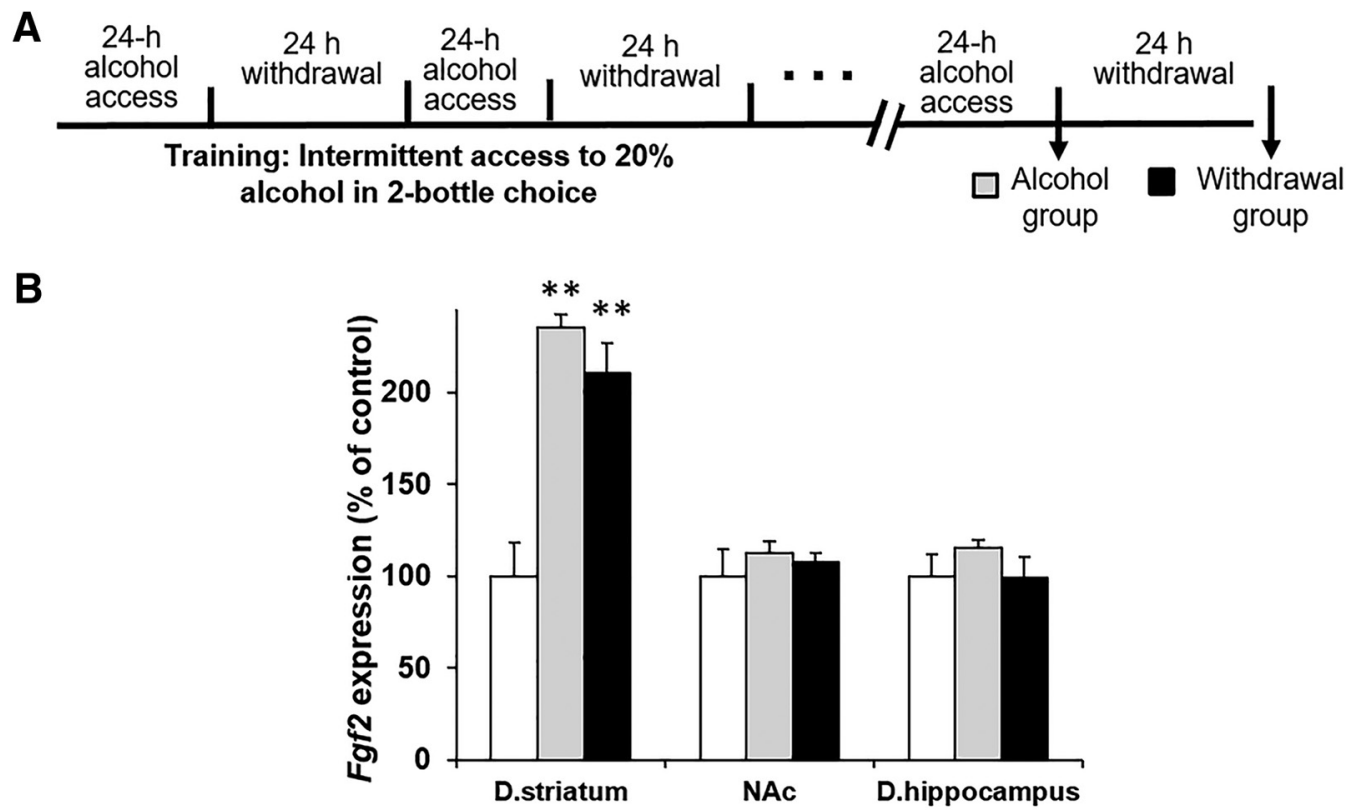

\section{$\square$ Water $\square$ Alcohol $\square$ Withdrawal}

Figure 3. Voluntary alcohol consumption increases Fgf2 expression in the dorsal striatum (D.striatum). $A$, Experimental timeline scheme. Mice consumed alcohol in the intermittent access to $20 \%$ alcohol in 2-bottle choice paradigm for 5 weeks. Control mice consumed water only. Tissues were collected immediately at the end of the last 24-h drinking session (Alcohol group) or $24 \mathrm{~h}$ after the termination of the last drinking session (Withdrawal group). B, Fgf2 mRNA levels were determined by qRT-PCR, and normalized to Gapdh, which was not affected by alcohol on its own (Fig. 1-1, available at https://doi.org/10.1523/JNEUROSCI.0890-17.2017.f1-1). Bar graphs indicate mean + SEM. Each brain region was normalized to its water control. $n=8$ or 9 per group. ${ }^{* *} p<0.01$ compared with water control.

erence $\sim 50 \pm 3.5 \%$ ) or after a 24 -h alcohol withdrawal period. Control mice consumed only water.

We found that alcohol consumption led to a $\sim 2.5$-fold increase in Fgf2 expression in the dorsal striatum, compared with water-drinking controls, and this increase was still detected after a 24-h alcohol withdrawal period (Fig. 3; one-way ANOVA, $F_{(2,22)}=$ 24.52, $p<0.0001$; post hoc, alcohol/withdrawal vs water, $p$ values $<0.0001)$. No changes were found in the expression of Fgf 2 in the dorsal hippocampus or the NAc ( $p$ values $>0.43$ ). These results suggest that long-term consumption of excessive levels of alcohol leads to a stable increase in $F g f 2$ expression, selectively in the dorsal striatum.

Systemic rFGF2 administration increases voluntary alcohol but not saccharin or sucrose consumption

Our results indicate that alcohol leads to an increased expression of Fgf2, and that this increase is still seen after $24 \mathrm{~h}$ of alcohol deprivation. Therefore, we next tested whether increasing the levels of FGF2 would affect alcohol consumption and preference.

Mice were trained to consume alcohol in the IA2BC procedure for 5 weeks, as detailed above. rFGF2 ( 40 or $80 \mu \mathrm{g} / \mathrm{kg}$ in two separate experiments, s.c.) or vehicle was injected $1 \mathrm{~h}$ before the beginning of the drinking session. We found that mice treated with $80 \mu \mathrm{g} / \mathrm{kg}$ rFGF2, but not $40 \mu \mathrm{g} / \mathrm{kg}$ rFGF2, consumed more alcohol compared with vehicle-treated mice (Fig. 4; $40 \mu \mathrm{g} / \mathrm{kg}$ : $\left.t_{(16)}=0.96, p=0.35 ; 80 \mu \mathrm{g} / \mathrm{kg}: t_{(12)}=2.63, p=0.022\right)$. Importantly, this effect was specific to alcohol, as water consumption and total fluid intake were not affected by rFGF2 ( $p$ values $>0.177$ ). In addition, we found a trend toward an increase in alcohol preference at $80 \mu \mathrm{g} / \mathrm{kg}\left(t_{(12)}=1.79, p=0.09\right)$.

Next, we tested whether the effects of rFGF2 are specific to alcohol or are due to a more generalized effect on reward con- sumption. Thus, we next tested whether rFGF2 also affects the consumption of sweetened solutions (saccharin, which has no caloric value, or sucrose, which, like alcohol, has caloric value). Mice were trained to consume saccharin $(0.005 \%, 0.03 \%)$ or sucrose $(0.2 \%, 1 \%)$ in an intermittent access 2-bottle choice (water and saccharin/sucrose) procedure for 3 weeks. $\mathrm{rFGF} 2(80 \mu \mathrm{g} / \mathrm{kg}$, s.c.) or vehicle was administered $1 \mathrm{~h}$ before the beginning of a drinking session. We found that rFGF2 had no effects on saccharin or sucrose intake or preference at any of the solution concentrations (Fig. 4G-J; $p$ values $>0.60$ ). Importantly, our data indicated an increase in saccharin and sucrose consumption as a function of their concentration (mixed-model ANOVA, saccharin: $F_{(1,19)}=$ $64.75, p<0.0001$; sucrose: $\left.F_{(1,22}=26.22, p<0.0001\right)$, ruling out the possibility that rFGF2 failed to increase the consumption of the sweet solutions due to a ceiling effect.

\section{Infusion of rFGF2 into the dorsal striatum increases} voluntary alcohol consumption and preference

We found that a history of excessive alcohol consumption led to upregulation of $F g f 2$ expression selectively in the dorsal striatum and that systemic administration of the growth factor increased alcohol intake. To test whether the latter effect is mediated by the dorsal striatum, we next infused rFGF2 into the dorsal striatum of rats with a long-history of excessive alcohol drinking.

Rats were trained to consume alcohol in the IA2BC drinking procedure for 7 weeks (Carnicella et al., 2014). In this drinking protocol, Wistar rats typically show an average alcohol consumption of 3.5-5.5 g/kg/24 h, which generates blood alcohol concentration of $>60 \mathrm{mg} / \mathrm{dl}$ after binge-like drinking during the first hours of drinking (Cippitelli et al., 2012; Carnicella et al., 2014). rFGF2 (200 ng/0.75 $\mu$ l per hemisphere) and vehicle were infused into the dorsal striatum in a counterbalanced within- 
A
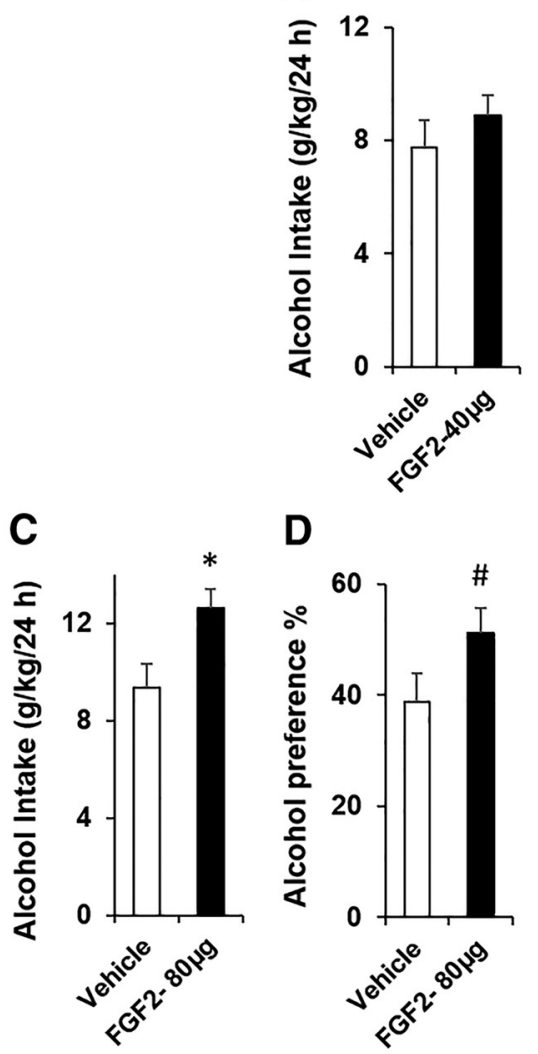

B

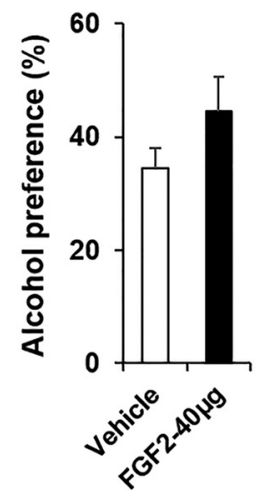

$E$
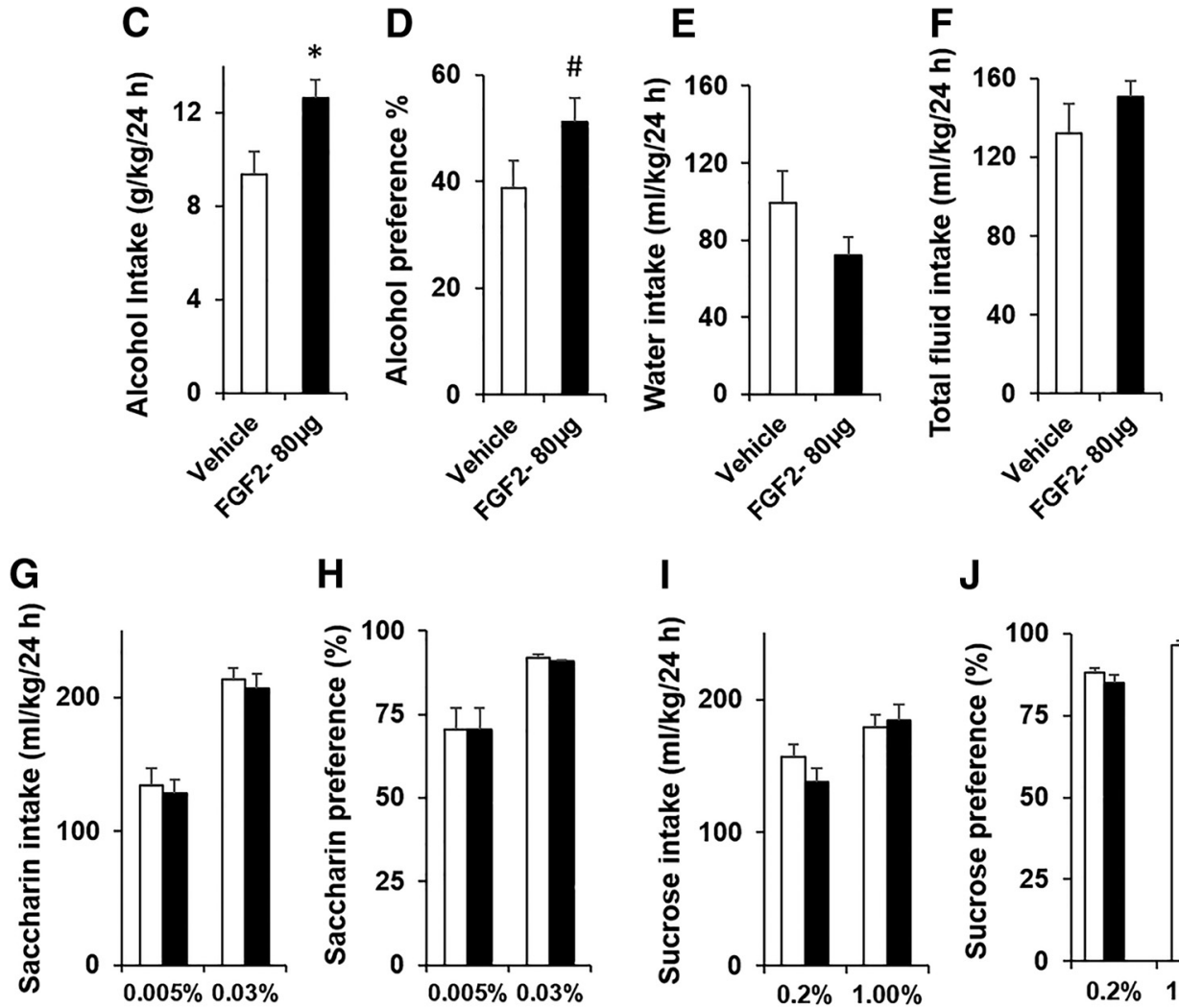
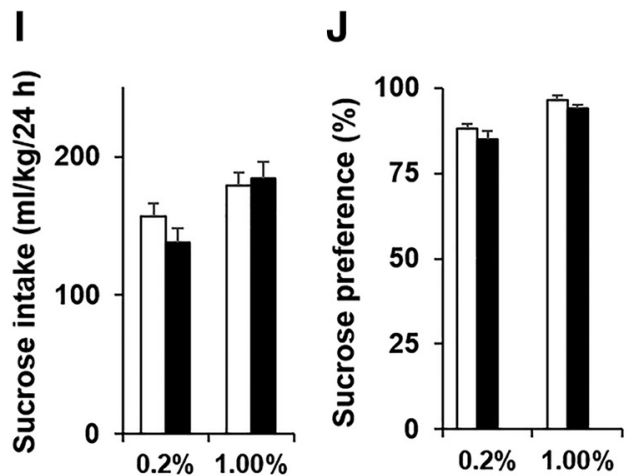

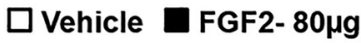

Figure 4. Systemic FGF2 administration increases alcohol, but not saccharin, sucrose, or water intake. Mice were trained to consume excessive amounts of $20 \%$ alcohol $(\boldsymbol{A}-\boldsymbol{F})$, saccharin $(\boldsymbol{G}, \boldsymbol{H})$, or sucrose $(I, J)$ solution in the intermittent access 2 -bottle choice paradigm. $A, B$, Recombinant FGF2 $(40 \mu \mathrm{g} / \mathrm{kg}$, s.c.) or vehicle was injected $1 \mathrm{~h}$ before the beginning of the $24 \mathrm{~h}$ alcohol-drinking test session. $\boldsymbol{A}$, Amount of alcohol $(\mathrm{g} / \mathrm{kg})$ consumed. $\boldsymbol{B}$, Preference for alcohol, calculated as the ratio of the volume of alcohol solution intake/volume of total fluid intake. $\boldsymbol{C}-\boldsymbol{J}$, Recombinant $\mathrm{FGF} 2$ $(80 \mu \mathrm{g} / \mathrm{kg} ; \mu \mathrm{g} / \mathrm{kg}$, s.c.) or vehicle was injected $1 \mathrm{~h}$ before the beginning of the $24 \mathrm{~h}$ alcohol $(\boldsymbol{C}-\boldsymbol{F})$, saccharin $(\boldsymbol{G}, \boldsymbol{H})$, or sucrose $(\boldsymbol{I}, \boldsymbol{J})$ drinking test session. $\boldsymbol{C}$, Amount of alcohol $(\mathrm{g} / \mathrm{kg})$ consumed. $\boldsymbol{D}$, Preference to alcohol. $\boldsymbol{E}$, Water intake (ml/kg). $\boldsymbol{F}$, Total fluid intake (alcohol + water; $\mathrm{ml} / \mathrm{kg}) . \mathbf{G}$, Saccharin $(0.005 \%$ or $0.03 \%)$ solution intake (ml $/ \mathrm{kg})$. $\boldsymbol{H}$, Preference for saccharin solution. I, Sucrose $(0.2 \%$ or $1 \%)$ solution intake (ml/kg). J, Preference for sucrose solution. Bar graphs indicate mean + SEM. $n=7-11$ per group. ${ }^{*} p<0.05$; ${ }^{*} p=0.09$.

subjects design, 10 min before the beginning of a 24 -h alcohol drinking session.

As depicted in Figure 5, we found that rFGF2 infusion increased alcohol consumption $\left(t_{(13)}=3.67, p=0.003\right)$ and preference $\left(t_{(13)}=2.60, p=0.022\right)$. rFGF2 did not alter water consumption ( $p=0.55)$, further indicating that the growth factor increased alcohol consumption without affecting other consummatory behaviors. Because alcohol intake was increased by rFGF2 without an effect on water intake, the total fluid intake was increased $\left(t_{(13)}=3.88, p=0.002\right)$. Interestingly, rFGF2 did not affect alcohol consumption or preference in the first $30 \mathrm{~min}$ or $4 \mathrm{~h}$ of drinking ( $p$ values $>0.12$ ). These results indicate that FGF2 in the dorsal striatum is an enhancer of alcohol consumption and that its action involves slow-onset mechanisms.

\section{The effect of excessive alcohol consumption on $\mathrm{Fg} 2$} expression is localized to the DMS

The dorsal striatum is divided into two anatomical and functional subregions: the DMS and the DLS. The DMS is implicated in goal-directed behavior (Yin et al., 2005; Yin and Knowlton, 2006) and is important for the early stages of alcohol consumption (Corbit et al., 2012). The DLS is implicated in habit learning 
A

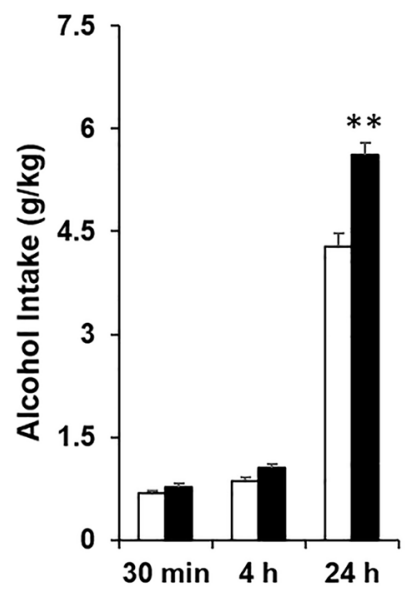

C

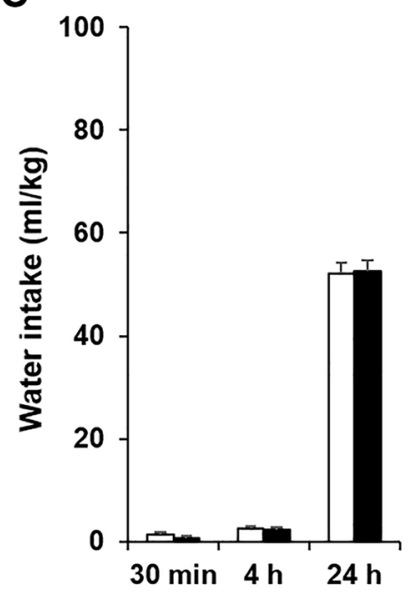

B

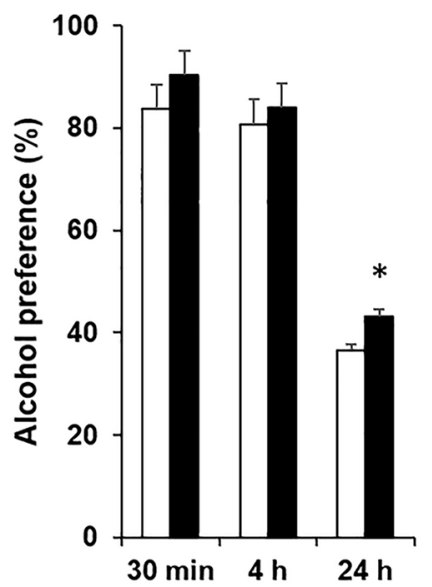

E

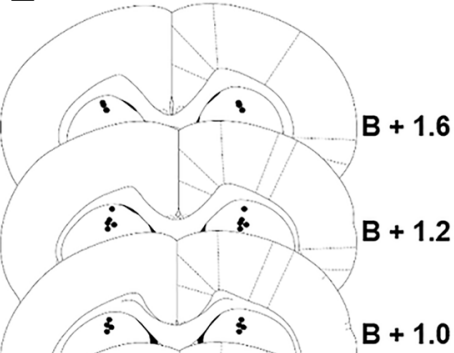

D

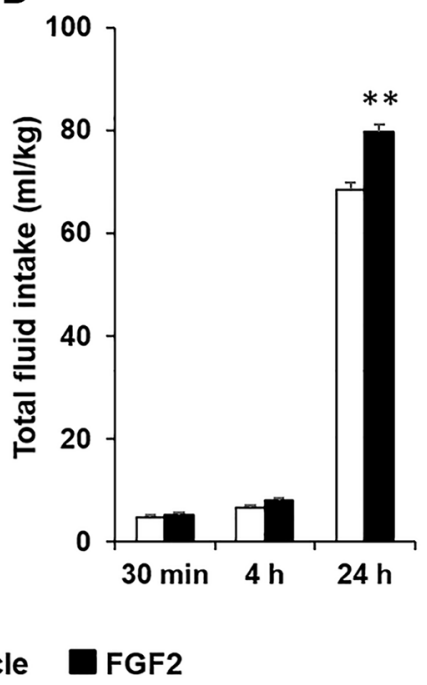

Figure 5. FGF2 infusion into the dorsal striatum leads to increased alcohol consumption and preference. Rats were trained to consume alcohol in the intermittent access to $20 \%$ alcohol in 2 -bottle choice paradigm for 7 weeks before cannulation. Recombinant FGF2 (200 ng/0.75 $\mu$ l per hemisphere) or vehicle was infused into the dorsal striatum, 10 min before the beginning of an alcohol-drinking session. Alcohol and water intake was measured after $30 \mathrm{~min}, 4 \mathrm{~h}$, and $24 \mathrm{~h}$. $A$, Amount of alcohol $(\mathrm{g} / \mathrm{kg})$ consumed. $\boldsymbol{B}$, Preference for alcohol, calculated as the ratio of the volume of alcohol solution intake/volume of total fluid intake. C, Water intake $(\mathrm{ml} / \mathrm{kg})$. D, Total fluid intake (alcohol + water; $\mathrm{ml} / \mathrm{kg}$ ). $\boldsymbol{E}$, Schematic representation of the cannula tip placement in coronal sections $($ bregma $+m m)$. Bar graphs indicate mean + SEM adjusted for a within-subjects design (Cousineau, 2005). $n=14$ per group. ${ }^{*} p<0.05 ;{ }^{* *} p<0.01$.

(White and McDonald, 2002; Featherstone and McDonald, 2004; Yin et al., 2004) and in compulsive alcohol/drug consumption (Everitt and Robbins, 2005; Corbit et al., 2012). Because we found that excessive voluntary alcohol intake led to upregulation of $F g 2$ expression in the dorsal striatum (Fig. 3), we next tested whether this effect was localized to the DMS and/or DLS.

We trained both mice and rats in the IA2BC procedure, as detailed above (average consumption in the last 24-h drinking session: mice, $\sim 15 \pm 0.79 \mathrm{~g} / \mathrm{kg}$, preference levels: $\sim 55 \pm 2.5 \%$; rats, $\sim 4.3 \pm$ $0.5 \mathrm{~g} / \mathrm{kg}$, preference levels: $\sim 55 \pm 7 \%$ ). Control rodents consumed only water. Because we observed increased levels of Fgf2 expression both after a 24-h alcohol-drinking session and after the following $24 \mathrm{~h}$ of withdrawal (Fig. $3 B$ ), here brains were collected only at the latter time point. This time point is of particular interest, as it corresponds to the beginning of the next alcohol-drinking session, as well as to the timing we administered rFGF2.

As depicted in Figure 6, we found that, following withdrawal from voluntary alcohol consumption, Fgf2 expression was upregulated in the DMS, but not in the DLS of both mice and rats. These results suggest that the striatal increases in Fgf2 expression, induced by excessive consumption of alcohol, are localized to the DMS (DMS: mice, $t_{(9)}=2.67, p=0.026$; rats, $t_{(10)}=2.37, p=$ 0.039; DLS: both species, $p$ values $>0.67)$.

\section{Infusion of rFGF2 into the DMS increases voluntary alcohol consumption and preference}

Because we found that withdrawal from excessive alcohol consumption increases $F g f 2$ expression selectively in the dorsomedial subregion of the striatum, we next tested whether the effects of rFGF2 on alcohol intake were also localized to this brain region. Rats were trained to consume alcohol in the IA2BC procedure for 7 weeks, as described above. rFGF2 (200 ng/0.75 $\mu$ l per hemisphere) and vehicle were infused into the DMS in a counterbalanced within-subjects design, $10 \mathrm{~min}$ before the beginning of a 24-h alcohol drinking session.

As shown in Figure 7, we found that rFGF2 treatment increased alcohol consumption and preference, compared with vehicle (paired $t$ test; consumption: $t_{(7)}=2.93, p=0.022$; preference: $\left.t_{(7)}=4.11, p=0.05\right)$. Moreover, although rFGF2 reduced water intake $\left(t_{(7)}=2.85, p=0.025\right)$, it did not affect 
A
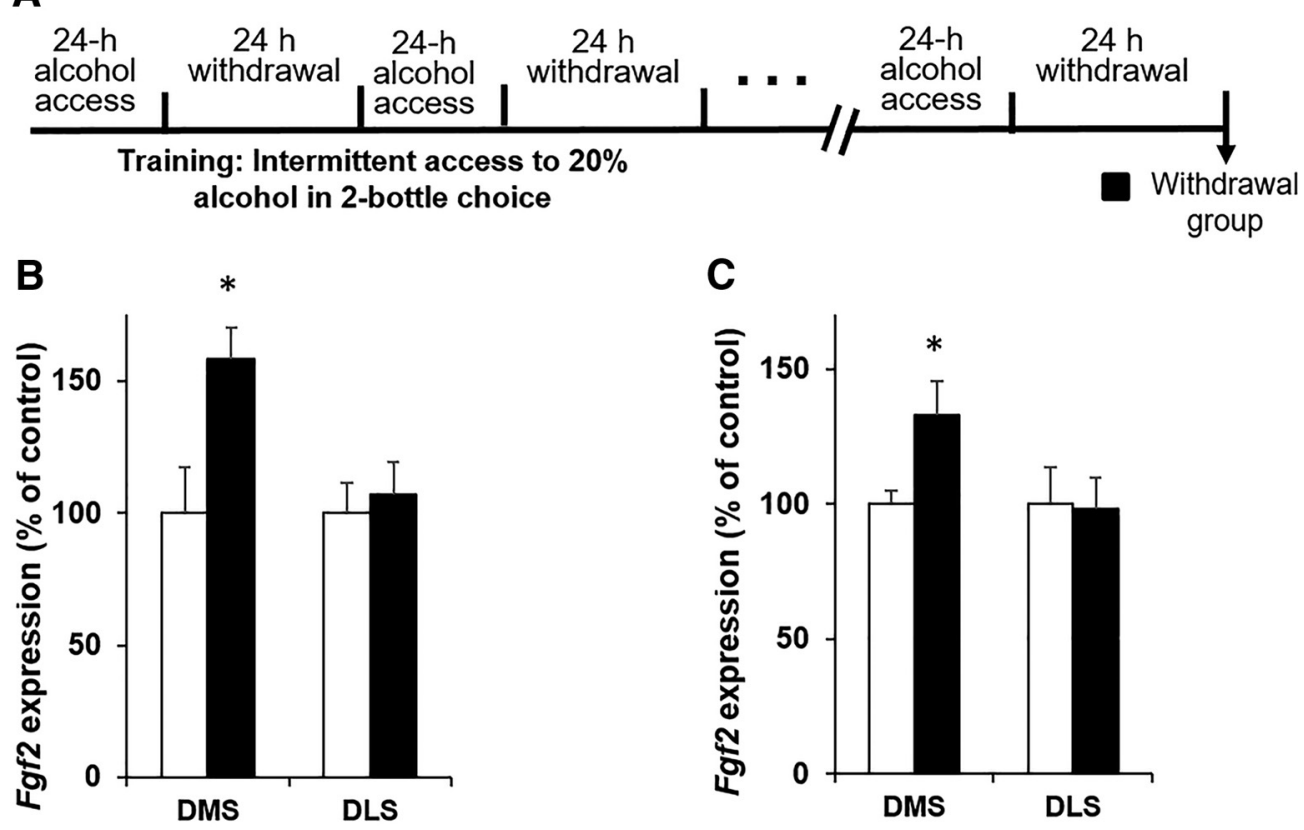

C

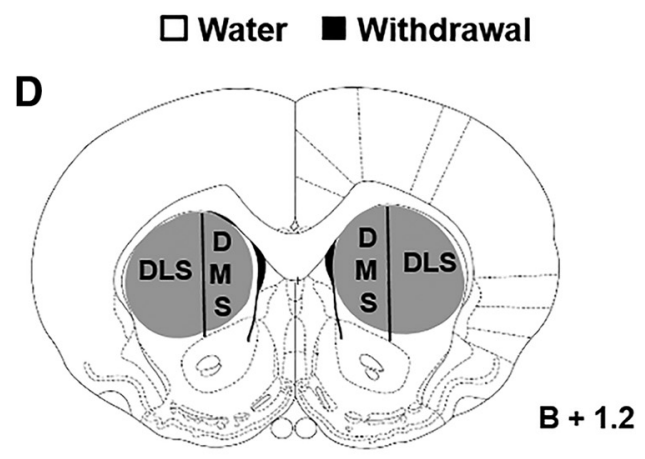

Figure 6. Voluntary alcohol consumption increases Fgf2 expression in the DMS of mice and rats. A, Experimental timeline scheme. Mice and rats consumed alcohol in the intermittent access to $20 \%$ alcohol in 2-bottle choice paradigm. Control animals consumed water only. Tissues were collected $24 \mathrm{~h}$ after the termination of the last drinking session (Withdrawal group). B, C, Fgf2 mRNA levels were determined by qRT-PCR in the DMS and DLS of mice $(\boldsymbol{B})$ and rats $(\boldsymbol{C})$, and normalized to Gapdh. Bar graphs indicate mean + SEM. Each brain region was normalized to its water control. $D$, Schematic representation of the sampling regions. $n=5$ or 6 per group. ${ }^{*} p<0.05$ compared with water control.

the total fluid intake ( $p=0.118$ ). These results suggest that increasing the levels of FGF2 in the DMS enhances alcohol consumption.

\section{Inhibition of FGF2 activity in the DMS reduces alcohol consumption and preference}

Our results suggest that FGF2 in the DMS is a positive regulator of alcohol intake. If so, inhibition of FGF2 activity in this brain region is expected to reduce alcohol consumption. Therefore, we next determined the effects of inhibition of FGF2 function in the DMS on alcohol intake. We used a neutralizing antibody against FGF2 (Mueller et al., 2006; Hafenbreidel et al., 2015) to inhibit the function of the growth factor. This neutralizing antibody selectively targets FGF2, with no cross-reactivity to FGF1 (Matsuzaki et al., 1989; Tao et al., 1997).

Rats were trained to consume alcohol in the IA2BC procedure, as described above. Anti-FGF2 neutralizing antibody (750 $\mathrm{ng} / 0.75 \mu \mathrm{l}$ per hemisphere) and control IgG were infused into the DMS in a counterbalanced within-subjects design, $1 \mathrm{~h}$ before the beginning of a $24 \mathrm{~h}$ alcohol drinking session.

As detailed in Figure 8, we found that inhibition of FGF2 function in the DMS suppressed alcohol consumption and prefer- ence, compared with the control treatment (paired $t$ test; consumption: $t_{(14)}=2.81, p=0.014$; preference: $\left.t_{(14)}=4.35, p=0.001\right)$. Although inhibition of FGF2 increased water intake $\left(t_{(14)}=2.90\right.$, $0.012)$, it did not affect the total fluid intake $(p=0.54)$. These results indicate that deceasing FGF2 activity in the DMS suppresses alcohol consumption, suggesting that the endogenous FGF2 positively regulates alcohol-drinking behavior.

\section{Discussion}

Our results demonstrate the involvement of FGF2 in alcoholdrinking behaviors, raising the possibility that this growth factor is involved in the escalation and maintenance of alcohol drinking. Our main findings are as follows: (1) a history of excessive alcohol drinking results in a sustained increase in Fgf 2 mRNA levels in the DMS; (2) rFGF2 increases alcohol consumption and preference, and its action is localized to the DMS; and (3) inhibition of the endogenous FGF2 in the DMS suppresses alcohol intake. Based on these findings, we propose that excessive alcohol drinking leads to elevated FGF2 levels in the DMS, which in turn promote excessive alcohol consumption. Thus, these bidirectional effects provide a positive regulatory feedback loop of alcohol and FGF2, possibly contributing to the escalation in alcohol intake. 
A

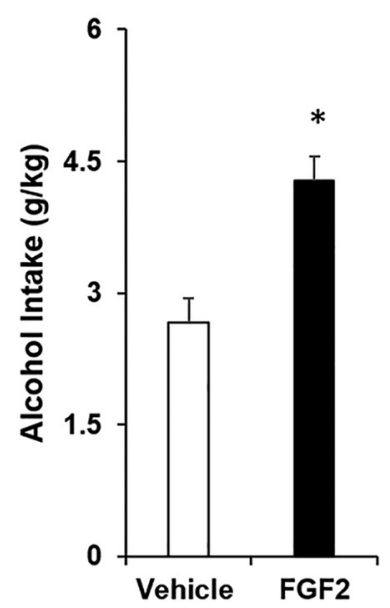

C

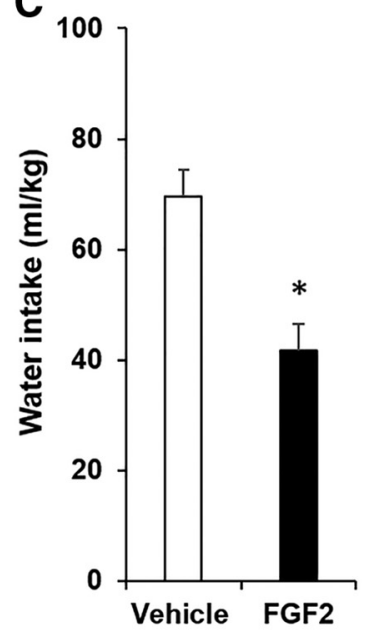

B

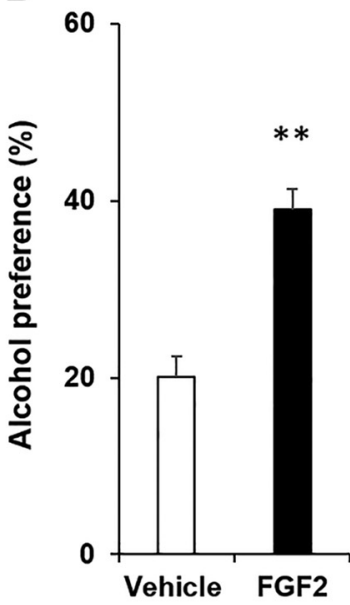

D

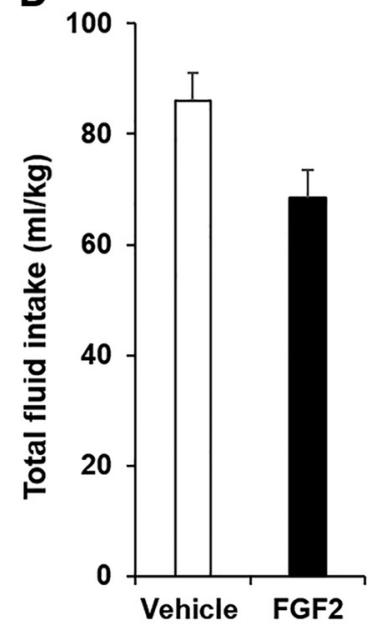

E

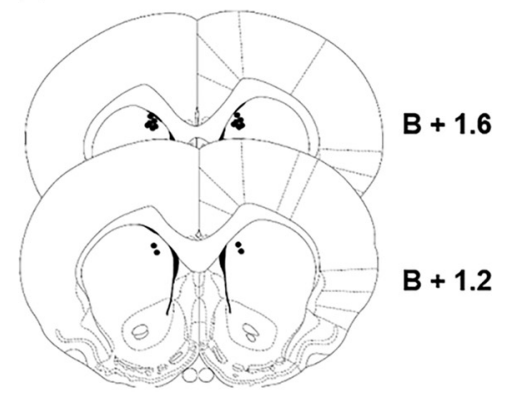

Figure 7. FGF2 infusion into the DMS increases alcohol consumption and preference. Rats were trained to consume alcohol in the intermittent access to $20 \%$ alcohol in 2-bottle choice paradigm for 7 weeks before cannulation. Recombinant FGF2 ( $200 \mathrm{ng} / 0.75 \mu$ l per hemisphere) or vehicle was infused into the DMS 10 min before the beginning of an alcohol-drinking session. Alcohol and water intake was measured at the end of the $24-\mathrm{h}$ drinking session. $\boldsymbol{A}$, Amount of alcohol $(\mathrm{g} / \mathrm{kg})$ consumed. $\boldsymbol{B}$, Preference for alcohol, calculated as the ratio of the volume of alcohol solution intake/volume of total fluid intake. C, Water intake $(\mathrm{ml} / \mathrm{kg})$. $\boldsymbol{D}$, Total fluid intake (alcohol + water; $\mathrm{ml} / \mathrm{kg}$ ). $\boldsymbol{E}$, Schematic representation of the cannula tip placement in coronal sections (bregma $+\mathrm{mm}$ ). Bar graphs indicate mean + SEM adjusted for a within-subjects design (Cousineau, 2005). $n=8$ per group. ${ }^{*} p<0.05 ;{ }^{* *} p<0.01$.

\section{FGF2 is an alcohol-responsive gene}

We show that acute alcohol exposure leads to increased expression of the Fgf 2 transcript in the NAc, dorsal striatum, and dorsal hippocampus. Interestingly, as alcohol exposure extended, its effects on $F g f 2$ expression became more specific and spatially restricted. Specifically, short-term exposure to alcohol (7 daily injections) increased Fgf2 expression only in the dorsal striatum shortly after the last injection, but the expression levels returned to baseline after $24 \mathrm{~h}$. Long-term voluntary consumption of excessive alcohol levels increased $F g f 2$ expression exclusively in the DMS. Thus, as the exposure to alcohol extends and becomes more robust, the effects on Fgf2 expression become more specific and stable.

We further show that the striatal increase in Fgf2 expression following repeated alcohol injections was blocked by haloperidol, suggesting that this effect is mediated via dopamine D2-like receptor activation. Given that alcohol injections increase dopamine levels in the dorsal striatum (Di Chiara and Imperato, 1988), it is likely that alcohol increases striatal $F g 2$ levels by increasing dopamine levels, which activate dopamine D2-like receptors. As haloperidol was reported to have low affinity to additional receptors (e.g., sigmal re- ceptor and $\alpha$-1a andrenoreceptor) (Walker et al., 1988; Richelson and Souder, 2000), we cannot rule out the involvement of these receptors in the effects of alcohol on Fgf2. Moreover, withdrawal from prolonged excessive alcohol drinking leads to an allostatic reduction in dopamine levels (Weiss et al., 1996; Barak et al., 2011a). Therefore, it is possible that, after a long period of alcohol exposure, additional mechanisms are involved in the upregulation of Fgf2 expression (e.g., glutamatergic or GABAergic neurotransmission), which were previously implicated in modulation of FGF2 expression (Riva et al., 1994; Flores and Stewart, 2000a; Gómez-Pinilla et al., 2000).

Importantly, it has previously been reported that increases in the Fgf 2 mRNA levels in the striatum, PFC, and hippocampus caused by nicotine (Roceri et al., 2001) and the D2R agonist quinpirole (Fumagalli et al., 2003) are accompanied by a similar increase in the FGF2 protein levels. Thus, it is likely that the transcriptional changes in Fgf2, which we observed, translate into changes in the protein levels.

\section{FGF2 positively regulates alcohol consumption}

Upon showing that Fgf2 expression is increased in the DMS after a history of excessive alcohol consumption, we show that FGF2 
A

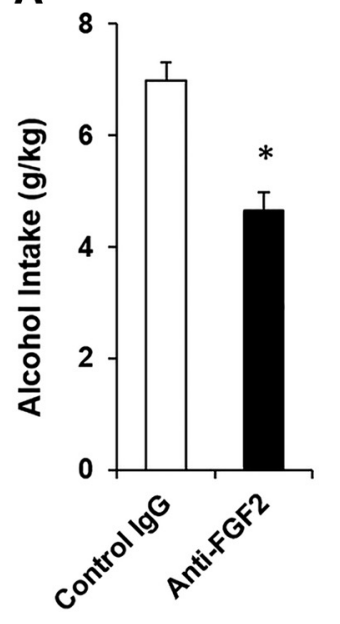

C

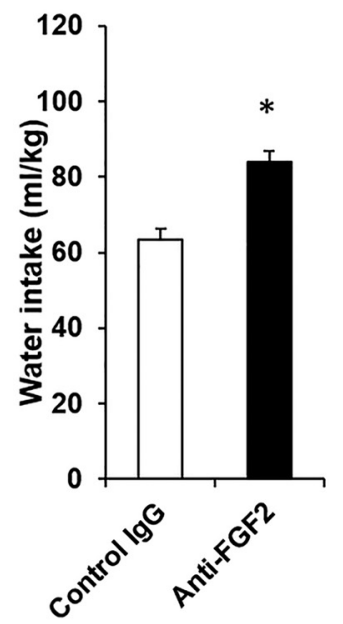

B

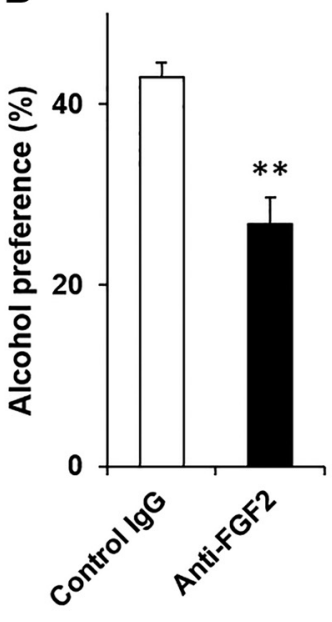

D

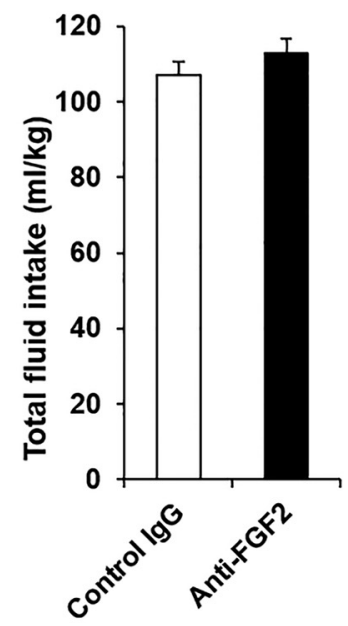

E

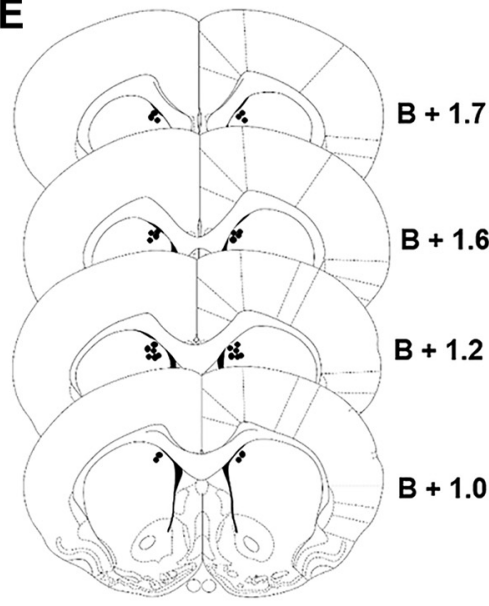

Figure 8. Inhibition of FGF2 activity in the DMS decreases alcohol consumption and preference. Rats were trained to consume alcohol in the intermittent access to $20 \%$ alcohol in 2-bottle choice paradigm for 7 weeks before cannulation. Neutralizing antibody against FGF2 (750 ng/0.75 $\mu$ l per hemisphere) or control lgG was infused into the DMS $1 \mathrm{~h}$ before the beginning of an alcoholdrinking session. Alcohol and water intake was measured at the end of the $24-\mathrm{h}$ drinking session. $\boldsymbol{A}$, Amount of alcohol $(\mathrm{g} / \mathrm{kg})$ consumed. $\boldsymbol{B}$, Preference for alcohol, calculated as the ratio of the volume of alcohol solution intake/volume of total fluid intake. C, Water intake $(\mathrm{ml} / \mathrm{kg})$. D, Total fluid intake (alcohol + water; $\mathrm{ml} / \mathrm{kg})$. E, Schematic representation of the cannula tip placement in coronal sections (bregma $+m m$ ). Bar graphs indicate mean + SEM adjusted for a within-subjects design (Cousineau, 2005). $n=15$ per group. ${ }^{*} p<0.05 ;{ }^{* *} p<0.01$.

regulates alcohol consumption. Specifically, systemic administration of rFGF2 to mice, as well as focal infusion of rFGF2 into the dorsal striatum, or more specifically into the DMS of rats, led to increased alcohol intake and preference. Importantly, the effect of rFGF2 was specific to alcohol, as it did not increase the consumption of water, saccharin, or sucrose. Interestingly, rFGF2 administration had no effects during the initial $4 \mathrm{~h}$ of the drinking session. This delayed-onset effect suggests that the actions of FGF2 may require transcriptional and/or translational mechanisms, which lead to increased alcohol intake in a delayed manner.

We further found that inhibition of the endogenous FGF2 in the rat DMS, by infusion of an anti-FGF2 neutralizing antibody, suppressed alcohol consumption and preference. These results indicate that the endogenous FGF2 function is required for consumption of high levels of alcohol. Together, our findings that bidirectional manipulations on FGF2 yield opposite effects on alcohol consumption provide strong evidence for the role of FGF2 in the DMS as a pivotal positive regulator of alcoholdrinking behaviors.

Relevantly, it was previously reported that inhibition of FGF2 in the VTA, by anti-FGF2 neutralizing antibody, blocked the de- velopment of amphetamine-induced psychomotor sensitization (Flores et al., 2000). Moreover, FGF2 inhibition in the infralimbic cortex enhanced extinction of operant cocaine self-administration (Hafenbreidel et al., 2015). Finally, rats selectively bred to show low novelty responses, which were shown to express reduced brain Fgf2 levels (Perez et al., 2009; Clinton et al., 2012), exhibited lower levels of operant cocaine self-administration (Cummings et al., 2011) and sensitization (Clinton et al., 2012), compared with controls. Together with the current findings, these findings suggest that the endogenous FGF2 regulates drug-related behaviors, including drug-seeking and consumption.

Interestingly, our finding that FGF2 is a positive regulator of alcohol consumption sets it apart from other growth factors that negatively regulate alcohol intake (Ghitza et al., 2010; Ron and Barak, 2016). Thus, downregulation of brain-derived neurotrophic factor $(B d n f)$ expression in the DLS (Jeanblanc et al., 2009; Logrip et al., 2015), or of glial cell line-derived neurotrophic factor $(G d n f)$ in the VTA or NAc (Ahmadiantehrani et al., 2014; Barak et al., 2015), increases alcohol consumption. Conversely, infusion of BDNF (Jeanblanc et al., 2009) or GDNF (Carnicella et al., 2008; Barak et al., 2011a, b) into these respective 
brain regions attenuates alcohol intake. These opposite effects of FGF2 and other growth factors may be due to their action at different brain regions and/or via different downstream processes.

\section{Alcohol and FGF2, a positive feedback regulatory loop for drinking escalation?}

We used here an alcohol-drinking protocol that consists of repeated cycles of $24 \mathrm{~h}$ alcohol consumption and withdrawal sessions. Critically, our findings indicate that $F g f 2$ expression levels in the DMS are still elevated after a 24-h withdrawal session, a time point that corresponds to the beginning of the next alcoholaccess session in this drinking protocol. Furthermore, administration of rFGF2 after a 24-h withdrawal period in the same drinking paradigm, either systemically to mice, or intra-dorsal striatum or intra-DMS to rats, increased alcohol drinking, whereas inhibition of FGF2 function at a similar time point had the opposite effect. These findings suggest that, throughout the alcohol drinking training, the increases in Fgf2 levels are likely leading to further increases in alcohol intake and preference in the next alcohol drinking sessions, possibly accounting for the escalation in drinking and maintaining high $F g f 2$ expression.

Interestingly, a positive feedback loop similar to the one we describe here with alcohol and FGF2 in the DMS has been reported with alcohol and AMPA receptor activity in the same brain region (Wang et al., 2012). Thus, it was shown that excessive alcohol consumption increases synaptic AMPA receptor levels and function in the DMS (Wang et al., 2012). Moreover, this AMPA receptor activity was shown to be vital for the expression of excessive alcohol consumption (Wang et al., 2012). Relatedly, FGF2 was reported to increase the expression of the AMPA receptor subunit GluR1 (Cheng et al., 1995; Chew et al., 1997), consequently increasing AMPA receptor function (Chew et al., 1997). Although these interactions remain to be tested, it is plausible that, within the DMS, alcohol increases FGF2 expression, which in turn increases AMPA receptor activity, resulting in excessive alcohol consumption.

We found that the bidirectional interaction between alcohol and FGF2 was localized to the DMS. This brain region was suggested to play a role in the early stages of alcohol consumption, which are governed primarily by goal-directed behavior, before the behavior becomes habitual (Corbit et al., 2012). Thus, the increase in FGF2 levels in the DMS, and its consequent enhancing effect on alcohol intake, may strengthen the response-outcome association, hence promoting engagement in alcohol-seeking and -drinking behaviors, and contributing to the development and maintenance of excessive alcohol-drinking behaviors.

Our results are in line with previous studies, which found that other drugs of abuse, such as amphetamine (Flores et al., 1998), cocaine (Flores and Stewart, 2000b; Fumagalli et al., 2006) and nicotine (Roceri et al., 2001), increase FGF2 levels in addictionrelated brain regions. In addition, the midbrain levels of FGF2 positively correlated with the magnitude of amphetamine psychomotor sensitization (Flores et al., 2000). Moreover, Fgf2 mRNA expression and its epigenetic modifications in the rat NAc positively correlated with cocaine seeking and relapse (Flagel et al., 2016). Finally, neonatal rFGF2 treatment enhanced cocaine self-administration and sensitization in adulthood (Turner et al., 2009; Clinton et al., 2012). Together with our present findings, these findings suggest that various drugs of abuse increase the brain expression of FGF2 and that high levels of FGF2 likely promote drug sensitization and consumption.
In conclusion, our results show that alcohol consumption increases the expression of Fgf2 within the DMS and that FGF2 increases alcohol intake by acting in this brain region. Therefore, our findings suggest that alcohol and FGF2 constitute a positive feedback loop, which contributes to the facilitation and maintenance of alcohol intake. Finally, together with previous reports, our findings suggest that FGF2 is a positive regulator of the consumption not only of alcohol, but also of other drugs of abuse.

\section{References}

Ahmadiantehrani S, Barak S, Ron D (2014) GDNF is a novel ethanolresponsive gene in the VTA: implications for the development and persistence of excessive drinking. Addict Biol 19:623-633. CrossRef Medline

American Psychiatric Association (2013) The diagnostic and statistical manual of mental disorders, Ed 5. Washington, DC: American Psychiatric Association.

Barak S, Ahmadiantehrani S, Kharazia V, Ron D (2011a) Positive autoregulation of GDNF levels in the ventral tegmental area mediates long-lasting inhibition of excessive alcohol consumption. Transl Psychiatry 1:360. CrossRef Medline

Barak S, Carnicella S, Yowell QV, Ron D (2011b) Glial cell line-derived neurotrophic factor reverses alcohol-induced allostasis of the mesolimbic dopaminergic system: implications for alcohol reward and seeking. JNeurosci 31:9885-9894. CrossRef Medline

Barak S, Liu F, Ben Hamida S, Yowell QV, Neasta J, Kharazia V, Janak PH, Ron D (2013) Disruption of alcohol-related memories by mTORC1 inhibition prevents relapse. Nat Neurosci 16:1111-1117. CrossRef Medline

Barak S, Wang J, Ahmadiantehrani S, Ben Hamida S, Kells AP, Forsayeth J, Bankiewicz KS, Ron D (2015) Glial cell line-derived neurotrophic factor (GDNF) is an endogenous protector in the mesolimbic system against excessive alcohol consumption and relapse. Addict Biol 20:629-642. CrossRef Medline

Berridge KC, Robinson TE (1998) What is the role of dopamine in reward: hedonic impact, reward learning, or incentive salience? Brain Res Brain Res Rev 28:309-369. CrossRef Medline

Carnicella S, Kharazia V, Jeanblanc J, Janak PH, Ron D (2008) GDNF is a fast-acting potent inhibitor of alcohol consumption and relapse. Proc Natl Acad Sci U S A 105:8114-8119. CrossRef Medline

Carnicella S, Ron D, Barak S (2014) Intermittent ethanol access schedule in rats as a preclinical model of alcohol abuse. Alcohol 48:243-252. CrossRef Medline

Cheng B, Furukawa K, O’Keefe JA, Goodman Y, Kihiko M, Fabian T, Mattson MP (1995) Basic fibroblast growth factor selectively increases AMPAreceptor subunit GluR1 protein level and differentially modulates $\mathrm{Ca}^{2+}$ responses to AMPA and NMDA in hippocampal neurons. J Neurochem 65:2525-2536. CrossRef Medline

Chew LJ, Fleck MW, Wright P, Scherer SE, Mayer ML, Gallo V (1997) Growth factor-induced transcription of GluR1 increases functional AMPA receptor density in glial progenitor cells. J Neurosci 17:227-240. Medline

Cippitelli A, Damadzic R, Singley E, Thorsell A, Ciccocioppo R, Eskay RL, Heilig M (2012) Pharmacological blockade of corticotropin-releasing hormone receptor 1 (CRH1R) reduces voluntary consumption of high alcohol concentrations in nondependent Wistar rats. Pharmacol Biochem Behav 100:522-529. CrossRef Medline

Clinton SM, Turner CA, Flagel SB, Simpson DN, Watson SJ, Akil H (2012) Neonatal fibroblast growth factor treatment enhances cocaine sensitization. Pharmacol Biochem Behav 103:6-17. CrossRef Medline

Corbit LH, Nie H, Janak PH (2012) Habitual alcohol seeking: time course and the contribution of subregions of the dorsal striatum. Biol Psychiatry 72:389-395. CrossRef Medline

Cousineau D (2005) Confidence intervals in within-subject designs: a simpler solution to Loftus and Masson's method. Tutorials Quant Methods Psychol 1:42-45. CrossRef

Cummings JA, Gowl BA, Westenbroek C, Clinton SM, Akil H, Becker JB (2011) Effects of a selectively bred novelty-seeking phenotype on the motivation to take cocaine in male and female rats. Biol Sex Differ 2:3. CrossRef Medline

Di Chiara G, Imperato A (1988) Drugs abused by humans preferentially increase synaptic dopamine concentrations in the mesolimbic system of 
freely moving rats. Proc Natl Acad Sci U S A 85:5274-5278. CrossRef Medline

Everitt BJ, Robbins TW (2005) Neural systems of reinforcement for drug addiction: from actions to habits to compulsion. Nat Neurosci 8:14811489. CrossRef Medline

Everitt BJ, Robbins TW (2013) From the ventral to the dorsal striatum: devolving views of their roles in drug addiction. Neurosci Biobehav Rev 37:1946-1954. CrossRef Medline

Featherstone RE, McDonald RJ (2004) Dorsal striatum and stimulusresponse learning: lesions of the dorsolateral, but not dorsomedial, striatum impair acquisition of a simple discrimination task. Behav Brain Res 150:15-23. CrossRef Medline

Flagel SB, Chaudhury S, Waselus M, Kelly R, Sewani S, Clinton SM, Thompson RC, Watson SJ Jr, Akil H (2016) Genetic background and epigenetic modifications in the core of the nucleus accumbens predict addiction-like behavior in a rat model. Proc Natl Acad Sci U S A 113:E2861-E2870. CrossRef Medline

Flores C, Stewart J (2000a) Basic fibroblast growth factor as a mediator of the effects of glutamate in the development of long-lasting sensitization to stimulant drugs: studies in the rat. Psychopharmacology 151:152-165. CrossRef Medline

Flores C, Stewart J (2000b) Changes in astrocytic basic fibroblast growth factor expression during and after prolonged exposure to escalating doses of amphetamine. Neuroscience 98:287-293. CrossRef Medline

Flores C, Rodaros D, Stewart J (1998) Long-lasting induction of astrocytic basic fibroblast growth factor by repeated injections of amphetamine: blockade by concurrent treatment with a glutamate antagonist. J Neurosci 18:9547-9555. Medline

Flores C, Samaha AN, Stewart J (2000) Requirement of endogenous basic fibroblast growth factor for sensitization to amphetamine. J Neurosci 20:RC55. Medline

Ford-Perriss M, Abud H, Murphy M (2001) Fibroblast growth factors in the developing central nervous system. Clin Exp Pharmacol Physiol 28:493503. CrossRef Medline

Fumagalli F, Bedogni F, Maragnoli ME, Gennarelli M, Perez J, Racagni G, Riva MA (2003) Dopaminergic D2 receptor activation modulates FGF-2 gene expression in rat prefrontal cortex and hippocampus. J Neurosci Res 74:74-80. CrossRef Medline

Fumagalli F, Pasquale L, Racagni G, Riva MA (2006) Dynamic regulation of fibroblast growth factor 2 (FGF-2) gene expression in the rat brain following single and repeated cocaine administration. J Neurochem 96:9961004. CrossRef Medline

Ghitza UE, Zhai H, Wu P, Airavaara M, Shaham Y, Lu L (2010) Role of BDNF and GDNF in drug reward and relapse: a review. Neurosci Biobehav Rev 35:157-171. CrossRef Medline

Gómez-Pinilla F, Vu L, Cotman CW (1995) Regulation of astrocyte proliferation by FGF-2 and heparan sulfate in vivo. J Neurosci 15:2021-2029. Medline

Gómez-Pinilla F, Dao L, Choi J, Ryba EA (2000) Diazepam induces FGF-2 mRNA in the hippocampus and striatum. Brain Res Bull 53:283-289. CrossRef Medline

Gonzales RA, Job MO, Doyon WM (2004) The role of mesolimbic dopamine in the development and maintenance of ethanol reinforcement. Pharmacol Ther 103:121-146. CrossRef Medline

Graham BM, Richardson R (2011) Intraamygdala infusion of fibroblast growth factor 2 enhances extinction and reduces renewal and reinstatement in adult rats. J Neurosci 31:14151-14157. CrossRef Medline

Griffin WC 3rd (2014) Alcohol dependence and free-choice drinking in mice. Alcohol 48:287-293. CrossRef Medline

Grothe C, Timmer M (2007) The physiological and pharmacological role of basic fibroblast growth factor in the dopaminergic nigrostriatal system. Brain Res Rev 54:80-91. CrossRef Medline

Hafenbreidel M, Twining RC, Rafa Todd C, Mueller D (2015) Blocking infralimbic basic fibroblast growth factor (bFGF or FGF2) facilitates extinction of drug seeking after cocaine self-administration. Neuropsychopharmacology 40:2907-2915. CrossRef Medline

Hwa LS, Chu A, Levinson SA, Kayyali TM, DeBold JF, Miczek KA (2011) Persistent escalation of alcohol drinking in C57BL/6J mice with intermittent access to 20\% ethanol. Alcohol Clin Exp Res 35:1938-1947. CrossRef Medline

Hwa LS, Debold JF, Miczek KA (2013) Alcohol in excess: CRF(1) receptors in the rat and mouse VTA and DRN. Psychopharmacology 225:313-327. CrossRef Medline

Jeanblanc J, He DY, McGough NN, Logrip ML, Phamluong K, Janak PH, Ron D (2006) The dopamine D3 receptor is part of a homeostatic pathway regulating ethanol consumption. J Neurosci 26:1457-1464. CrossRef Medline

Jeanblanc J, He DY, Carnicella S, Kharazia V, Janak PH, Ron D (2009) Endogenous BDNF in the dorsolateral striatum gates alcohol drinking. J Neurosci 29:13494-13502. CrossRef Medline

Koob GF (2013) Theoretical frameworks and mechanistic aspects of alcohol addiction: alcohol addiction as a reward deficit disorder. Curr Top Behav Neurosci 13:3-30. CrossRef Medline

Koob GF, Volkow ND (2010) Neurocircuitry of addiction. Neuropsychopharmacology 35:217-238. CrossRef Medline

Koob GF, Volkow ND (2016) Neurobiology of addiction: a neurocircuitry analysis. Lancet Psychiatry 3:760-773. CrossRef Medline

Logrip ML, Vendruscolo LF, Schlosburg JE, Koob GF, Zorrilla EP (2014) Phosphodiesterase $10 \mathrm{~A}$ regulates alcohol and saccharin self-administration in rats. Neuropsychopharmacology 39:1722-1731. CrossRef Medline

Logrip ML, Barak S, Warnault V, Ron D (2015) Corticostriatal BDNF and alcohol addiction. Brain Res 1628:60-67. CrossRef Medline

Matsuzaki K, Yoshitake Y, Matuo Y, Sasaki H, Nishikawa K (1989) Monoclonal antibodies against heparin-binding growth factor II/basic fibroblast growth factor that block its biological activity: invalidity of the antibodies for tumor angiogenesis. Proc Natl Acad Sci U S A 86:99119915. CrossRef Medline

McGough NN, He DY, Logrip ML, Jeanblanc J, Phamluong K, Luong K, Kharazia V, Janak PH, Ron D (2004) RACK1 and brain-derived neurotrophic factor: a homeostatic pathway that regulates alcohol addiction. J Neurosci 24:10542-10552. CrossRef Medline

Mueller D, Chapman CA, Stewart J (2006) Amphetamine induces dendritic growth in ventral tegmental area dopaminergic neurons in vivo via basic fibroblast growth factor. Neuroscience 137:727-735. CrossRef Medline

Neasta J, Ben Hamida S, Yowell Q, Carnicella S, Ron D (2010) Role for mammalian target of rapamycin complex 1 signaling in neuroadaptations underlying alcohol-related disorders. Proc Natl Acad Sci U S A 107: 20093-20098. CrossRef Medline

Nestler EJ (2001) Molecular basis of long-term plasticity underlying addiction. Nat Rev Neurosci 2:119-128. CrossRef Medline

Paxinos G, Watson C (2007) The rat brain in stereotaxic coordinates, Ed 6. San Diego: Academic.

Perez JA, Clinton SM, Turner CA, Watson SJ, Akil H (2009) A new role for FGF2 as an endogenous inhibitor of anxiety. J Neurosci 29:6379-6387. CrossRef Medline

Reuss B, Unsicker K (2000) Survival and differentiation of dopaminergic mesencephalic neurons are promoted by dopamine-mediated induction of FGF-2 in striatal astroglial cells. Mol Cell Neurosci 16:781-792. CrossRef Medline

Reuss B, von Bohlen und Halbach O (2003) Fibroblast growth factors and their receptors in the central nervous system. Cell Tissue Res 313:139157. CrossRef Medline

Richelson E, Souder T (2000) Binding of antipsychotic drugs to human brain receptors. Life Sci 68:29-39. CrossRef Medline

Riva MA, Donati E, Tascedda F, Zolli M, Racagni G (1994) Short- and longterm induction of basic fibroblast growth factor gene expression in rat central nervous system following kainate injection. Neuroscience 59:5565. CrossRef Medline

Robinson TE, Berridge KC (2001) Incentive-sensitization and addiction. Addiction 96:103-114. CrossRef Medline

Roceri M, Molteni R, Fumagalli F, Racagni G, Gennarelli M, Corsini G, Maggio R, Riva M (2001) Stimulatory role of dopamine on fibroblast growth factor-2 expression in rat striatum. J Neurochem 76:990-997. CrossRef Medline

Ron D, Barak S (2016) Molecular mechanisms underlying alcohol-drinking behaviours. Nat Rev Neurosci 17:576-591. CrossRef Medline

Russo SJ, Dietz DM, Dumitriu D, Morrison JH, Malenka RC, Nestler EJ (2010) The addicted synapse: mechanisms of synaptic and structural plasticity in nucleus accumbens. Trends Neurosci 33:267-276. CrossRef Medline

Spanagel R (2009) Alcoholism: a systems approach from molecular physiology to addictive behavior. Physiol Rev 89:649-705. CrossRef Medline

Tao Y, Black IB, DiCicco-Bloom E (1997) In vivo neurogenesis is inhibited 
by neutralizing antibodies to basic fibroblast growth factor. J Neurobiol 33:289-296. CrossRef Medline

Turner CA, Gula EL, Taylor LP, Watson SJ, Akil H (2008) Antidepressantlike effects of intracerebroventricular FGF2 in rats. Brain Res 1224:63-68. CrossRef Medline

Turner CA, Capriles N, Flagel SB, Perez JA, Clinton SM, Watson SJ, Akil H (2009) Neonatal FGF2 alters cocaine self-administration in the adult rat. Pharmacol Biochem Behav 92:100-104. CrossRef Medline

Wagner JP, Black IB, DiCicco-Bloom E (1999) Stimulation of neonatal and adult brain neurogenesis by subcutaneous injection of basic fibroblast growth factor. J Neurosci 19:6006-6016. Medline

Walicke P, Cowan WM, Ueno N, Baird A, Guillemin R (1986) Fibroblast growth factor promotes survival of dissociated hippocampal neurons and enhances neurite extension. Proc Natl Acad Sci U S A 83:3012-3016. CrossRef Medline

Walker JM, Matsumoto RR, Bowen WD, Gans DL, Jones KD, Walker FO (1988) Evidence for a role of haloperidol-sensitive sigma-'opiate' receptors in the motor effects of antipsychotic drugs. Neurology 38:961-965. CrossRef Medline

Wang J, Carnicella S, Phamluong K, Jeanblanc J, Ronesi JA, Chaudhri N, Janak PH, Lovinger DM, Ron D (2007) Ethanol induces long-term facilitation of NR2B-NMDA receptor activity in the dorsal striatum: implications for alcohol drinking behavior. J Neurosci 27:3593-3602. CrossRef Medline

Wang J, Lanfranco MF, Gibb SL, Ron D (2011) Ethanol-mediated longlasting adaptations of the NR2B-containing NMDA receptors in the dorsomedial striatum. Channels (Austin) 5:205-209. CrossRef Medline

Wang J, Ben Hamida S, Darcq E, Zhu W, Gibb SL, Lanfranco MF, Carnicella
S, Ron D (2012) Ethanol-mediated facilitation of AMPA receptor function in the dorsomedial striatum: implications for alcohol drinking behavior. J Neurosci 32:15124-15132. CrossRef Medline

Warnault V, Darcq E, Levine A, Barak S, Ron D (2013) Chromatin remodeling-a novel strategy to control excessive alcohol drinking. Transl Psychiatry 3:e231. CrossRef Medline

Weiss F, Parsons LH, Schulteis G, Hyytiä P, Lorang MT, Bloom FE, Koob GF (1996) Ethanol self-administration restores withdrawal-associated deficiencies in accumbal dopamine and 5-hydroxytryptamine release in dependent rats. J Neurosci 16:3474-3485. Medline

White NM, McDonald RJ (2002) Multiple parallel memory systems in the brain of the rat. Neurobiol Learn Mem 77:125-184. CrossRef Medline

Wise RA (2009) Roles for nigrostriatal-not just mesocorticolimbic-dopamine in reward and addiction. Trends Neurosci 32:517-524. CrossRef Medline

World Health Organization (2014) Global status report on alcohol and health-2014. Geneva: World Health Organization.

Yin HH, Knowlton BJ (2006) The role of the basal ganglia in habit formation. Nat Rev Neurosci 7:464-476. CrossRef Medline

Yin HH, Knowlton BJ, Balleine BW (2004) Lesions of dorsolateral striatum preserve outcome expectancy but disrupt habit formation in instrumental learning. Eur J Neurosci 19:181-189. CrossRef Medline

Yin HH, Ostlund SB, Knowlton BJ, Balleine BW (2005) The role of the dorsomedial striatum in instrumental conditioning. Eur J Neurosci 22: 513-523. CrossRef Medline

Zipori D, Sadot-Sogrin Y, Goltseker K, Even-Chen O, Rahamim N, Shaham O, Barak S (2017) Re-exposure to nicotine-associated context from adolescence enhances alcohol intake in adulthood. Sci Rep 7:2479. CrossRef Medline 